\title{
PENINGKATAN PEMAHAMAN MODUL PENGANTAR STATISTIKA MELALUI DISKUSI EKSPLORATIF YANG MENEKANKAN PENGETAHUAN METAKOGNITIF PADA MAHASISWA S1 PGSD POKJAR SIDOARJO
}

\author{
Tri Dyah Prastiti (tridyahprastiti@ut.ac.id) \\ FKIP-UT, Jl. Cabe Raya, Pondok Cabe, Pamulang, Kota Tangerang Selatan \\ Jackson Pasini Mairing \\ FKIP Universitas Palangkaraya
}

\begin{abstract}
Recently, the phenomenon of the tutorial activities in mathematics class shown that the tutee still passive and just tended to accept tutor explanations. It made mathematics was considered as a difficult subject. Based on this reason, the authors conducted research on tutorial focused to improvement the students'abilities in Pengantar Statistika I dan II by using explorative discussion that emphasizes on the metacognitive knowledge level. The subjects are S1-PGSD students at second semester in Sidoarjo. The research is conducted in two cycles and shown that the use of the explorative discussion method that emphasizes on the metacognitive knowledge level is able to increase of the students' understanding and independence.
\end{abstract}

Keywords: explorative discussion, metacognitive knowledge, understanding

Salah satu mata kuliah yang dianggap "sulit" oleh mahasiswa semester II S1 PGSD adalah Matematika (PDGK 4108). Hal ini karena modul-modul dalam mata kuliah ini memerlukan pengetahuan matematika prasyarat yang cukup baik. Adapun modul-modul dalam Buku Materi Pokok mata kuliah Matematika (PDGK 4108) adalah: (1) logika, (2) penalaran dan sistem matematika, (3) persamaan dan pertidaksamaan linear, (4) persamaan dan pertidaksamaan kuadrat, (5) himpunan, relasi dan fungsi, (6) peluang, (7) aritmetika sosial, (8) pengangar statistika I, (9) pengantar statistika II, (10) pemecahan masalah, (11) transformasi, dan (12) kekongruenan dan kesebangunan.

Kesulitan pada mata kuliah ini juga dialami oleh mahasiswa semester II S1 PGSD pokjar Sidoarjo yang ditunjukkan dari hasil tes awal yang dilakukan peneliti pada modul Pengantar Statistika I dan II. Tes awal pada modul Pengantar Statistika I dilaksanakan pada hari Minggu, 16 Agustus 2009 di Kelas A dan B, sedangkan tes awal Pengantar Statistika II dilaksanakan pada hari Minggu, 23 Agustus 2009 juga di Kelas A dan B. Hasil tes awal tersebut adalah sebagai berikut.

Tabel 1. Rata-rata Hasil Tes Awal pada Mata Kuliah Matematika

\begin{tabular}{lcc}
\hline Mata Kuliah & Kelas A & Kelas B \\
\hline Pengantar Statistika I & 0 & 15,3 \\
Pengantar Statistika II & 25,5 & 44,5 \\
\hline
\end{tabular}

Soal-soal yang diberikan pada tes awal adalah soal-soal yang menggali pemahaman konsep pada materi-materi yang pernah dipelajari waktu sekolah menengah atas (SMA). Materi tersebut adalah penyajian data dan ukuran pemusatan. Nilai yang rendah ini menunjukkan bahwa selama ini 
mahasiswa mempelajari matematika hanya untuk menyelesaikan soal-soal yang bersifat prosedural. Sebagai contoh, sebagian besar mahasiswa mengetahui bagaimana mencari rata-rata, median dan modus. Akan tetapi kebanyakan dari mereka tidak mengetahui makna statistik-statistik tersebut sebagai ukuran pemusatan. Bahkan para mahasiswa tidak mengetahui apa yang dimaksud dengan ukuran pemusatan itu sendiri.

Penyajian data dan ukuran pemusatan merupakan salah satu materi pada modul Pengantar Statistika I dan II di mata kuliah Matematika, yang diberikan secara berurutan. Pada modul Pengantar Statistika I, mahasiswa diharapkan dapat: (1) menyajikan data ke dalam bentuk tabel dan diagram, dan (2) menyajikan data berkelompok ke dalam bentuk tabel distribusi frekuensi dan ke dalam bentuk diagram. Sedangkan pada modul Pengantar Statistika II, mahasiswa diharapkan dapat menyelesaikan permasalahan tentang ukuran pemusatan, ukuran letak dan ukuran penyebaran.

Untuk itu diperlukan usaha memperbaiki kondisi di atas sehingga mahasiswa memiliki pemahaman yang mendalam dan sikap kemandirian dalam belajar. Salah satu usaha adalah dengan menerapkan metode belajar yang mendorong hal-hal tersebut. Metode belajar itu adalah diskusi eksploratif yang menekankan pada pengetahuan metakognitif menggunakan tugas/proyek. Mengapa metode ini yang dipilih? Alasannya adalah dengan diskusi eksploratif diharapkan tutor dapat menghindarkan diri dari pemberian informasi semata dan dapat lebih mendorong terjadinya interaksi di antara mahasiswa. Melalui diskusi yang ditekankan pada pengetahuan metakognitif, mahasiswa diharapkan memperoleh pengetahuan yang mendalam mengenai materi yang dipelajarinya. Selain itu, tugas/proyek yang dikerjakan secara berkelompok di luar jam tutorial dapat mendorong mahasiswa bersifat mandiri dalam kerangka kerja kelompok. Tujuan penelitian ini adalah meningkatkan pemahaman dan kemandirian mahasiswa S1 PGSD Pokjar Sidoarjo pada modul Pengantar Statistika I dan II melalui tutorial perbaikan dengan metode diskusi eksploratif yang menekankan pada pengetahuan metakognitif.

Tutorial adalah bantuan atau bimbingan belajar yang bersifat akademik, yang diberikan oleh seseorang (tutor) kepada mahasiswa (tutee) untuk membantu kelancaran proses belajar mandiri mahasiswa secara perorangan atau kelompok, berkaitan dengan materi. Tutorial dilaksanakan secara tatap muka atau jarak jauh berdasarkan konsep belajar mandiri. Beberapa prinsip dasar tutorial yang sebaiknya dipenuhi oleh tutor agar penyelenggaraan tutorial efektif, dan tidak terjebak pada situasi perkuliahan biasa adalah sebagai berikut.

(1) Interaksi tutor-mahasiswa sebaiknya berlangsung pada tingkat metakognitif, yaitu tingkat berpikir yang menekankan pada pembentukan ketrampilan "learning how to learn" atau "think how to think" (mengapa demikian, bagaimana hal itu bisa terjadi, dsb).

(2) Tutor harus membimbing mahasiswa dengan teliti dalam keseluruhan langkah proses belajar yang dijalani mahasiswa.

(3) Tutor harus mampu mendorong mahasiswa sampai pada taraf pengertian (understanding) yang mendalam sehingga mampu menghasilkan pengetahuan (create) yang tahan lama.

(4) Tutor seyogyanya menghindarkan diri dari pemberian informasi semata (transfer of knowledge/information) dan menantang mahasiswa untuk menggali informasi/pengetahuan sendiri dari berbagai sumber belajar dan pengalaman lapangan.

(5) Tutor sebaiknya menghindarkan diri dari upaya memberikan pendapat terhadap kebenaran dan kualitas komentar atau sumbang pikiran (brainstorming) mahasiswa. 
(6) Tutor harus mampu menumbuhkan diskusi, komentar dan kritik antar mahasiswa, sehingga dapat meningkatkan kemampuan intelektual, psikomotorik, sikap demokrasi, kerjasama, dan interaksi antarmahasiswa.

(7) Segala keputusan dalam tutorial sebaiknya diambil melalui proses dinamika kelompok di mana setiap mahasiswa dalam kelompok memberikan sumbang pikirannya.

(8) Tutor sebaiknya menghindari pola interaksi tutor-mahasiswa dan mengembangkan pola interaksi mahasiswa-mahasiswa.

(9) Tutor perlu melakukan pelacakan lebih jauh (probing) terhadap setiap kebenaran jawaban atau pendapat mahasiswa untuk lebih menyakinkan mahasiswa atas kebenaran jawaban atau pendapat yang dikemukakan mahasiswa.

(10) Tutor seyogyanya mampu membuat variasi stimulasi/rangsangan untuk belajar sehingga mahasiswa tidak merasa bosan, jenuh, dan/atau putus asa.

(11) Tutor selayaknya memantau kualitas kemajuan belajar mahasiswa dengan mengarahkan kajian sampai pada taraf pengertian yang mendalam (indepth understanding).

(12) Tutor perlu menyadari kemungkinan munculnya potensi masalah interpersonal dalam kelompok, dengan segera melakukan intervensi skala kecil untuk memelihara aktivitas proses kerja dan dinamika kelompok.

(13) Tutor perlu senantiasa bekerjasama (power with) dengan mahasiswa dan selalu bertanggungjawab atas proses belajar dalam kelompok. Akan tetapi, sewaktu-waktu tutor juga harus lepas tangan (power off) bila proses belajar mahasiswa telah berjalan dengan baik.

Metakognisi adalah pengetahuan, kesadaran, dan kontrol serta pengelolaan penggunaan pikiran kita terhadap proses kognitif kita, sehingga seakan-akan kita berdiri di luar kepala kita dan mencoba merenungkan cara kita berpikir atau proses kognitif yang kita lakukan. Metakognisi adalah kesadaran seseorang terhadap proses dan hasil berpikirnya, dalam mengembangkan perencanaan, memonitor pelaksanaan dan mengevaluasi suatu tindakan. Jadi dengan metakognisi, seseorang akan "tahu bahwa ia tahu dan tahu bahwa tidak tahu" ("know that you know and know that you do not know")

Menurut NCREL dari Strategic Teaching and Reading Project Guidebook. (dalam http://members.ïnet.net.au/ rstack1/world/rss/files/metacognition. html,1995) metakognisi terdiri dari tiga elemen dasar berikut.

1. Developing a plan of action - mengembangkan rencana tindakan

2. Maintaining/monitoring the plan - memonitor rencana tindakan

3. Evaluating the plan - mengevaluasi rencana tindakan

Ketika mengembangkan rencana tindakan (sebelum tindakan), tanya pada diri sendiri:

1. Pengetahuan awal apa yang bisa membantuku memecahkan tugas ini?

2. Ke arah mana pikiranku ini akan membawaku?

3. Apa yang pertama kali harus aku lakukan?

4. Mengapa aku membaca bagian ini?

5. Berapa lama aku harus memecahkan tugas ini?

Ketika memonitor rencana tindakan (selama tindakan), tanya pada diri sendiri:

1. Bagaimana aku melakukannya? 
2. Apakah aku sudah berada di jalan yang benar?

3. Bagaimana seharusnya aku melanjutkannya?

4. Informasi apa yang penting untuk diingat?

5. Haruskah aku pindah ke cara yang berbeda?

6. Haruskah aku melakukan penyesuaian langkah berkaitan dengan kesulitan?

Ketika mengevaluasi rencana tindakan (sesudah tindakan), tanya pada diri sendiri:

1. Seberapa baik yang telah aku lakukan?

2. Apakah wacana berpikir khusus ini akan menghasilkan hasil yang lebih atau kurang dari yang aku harapkan?

3. Apakah aku sudah dapat melakukan dengan cara yang berbeda?

4. Mungkinkah aku menerapkan cara ini untuk masalah yang lain?

5. Apakah aku perlu kembali ke tugas awal untuk memenuhi bagian pemahaman saya yang kurang?

Pengetahuan metakognitif adalah pengetahuan seseorang mengenai proses berpikirnya yang merupakan perspektif pribadi dari kemampuan kognitifnya dibandingkan dengan kemampuan orang lain. Pengalaman metakognitif adalah pengalaman kognitif atau afektif yang menyertai dan berhubungan dengan semua kegiatan kognitif. Dengan kata lain, pengalaman metakognitif adalah pertimbangan secara sadar dari pengalaman intelektual yang menyertai kegagalan atau kesuksesan dalam pelajaran. Tujuan atau tugas mengacu pada tujuan berpikir, seperti membaca dan memahami suatu bagian untuk kuis mendatang, yang akan mencetuskan penggunaan pengetahuan metakognitif dan mendorong ke pengalaman metakognitif baru. Tindakan atau strategi mengacu pada berpikir atau perilaku yang khusus yang digunakan untuk melaksanakannya, yang dapat membantu untuk mencapai tujuan. Sebagai contoh, suatu pengalaman metakognitif dapat mengingatkan bahwa menggambarkan gagasan utama dari suatu bagian pada kesempatan sebelumnya dapat membantu meningkatkan pemahaman.

Pengetahuan metakognitif mengacu pada pengetahuan umum tentang bagaimana manusia belajar dan memproses informasi, seperti halnya pengetahuan individu mengenai proses pelajaran diri sendiri. Pernyataan bahwa "aku adalah ahli dalam aritmatika, tetapi ternyata Bobi mengetahui lebih dibanding aku" adalah suatu contoh pengetahuan metakognitif. Atau "aku menyadari, lebih baik aku bekerja di perpustakaan dari pada di rumah, karena di rumah lebih banyak gangguan. Pernyataan Flavell (1979) bahwa pengetahuan metakognitif terdiri dari pengetahuan utama atau kepercayaan tentang variabel atau faktor apa yang berlaku dan saling berhubungan.

\section{METODOLOGI}

Penelitian ini merupakan penelitian tindakan kelas (PTK). Lokasi penelitian adalah mahasiswa semester II PGSD S1 Pokjar Sidoarjo tahun 2009. Sedangkan, waktu penelitian JuliOktober 2009. Subjek penelitian adalah mahasiswa semester II PGSD S1 Pokjar Sidoarjo tahun 2009 yang terdiri dari 2 kelas yaitu kelas A dan B yang masing-masing berjumlah 30 dan 32 orang.

Pelaksanan masing-masing tindakan dalam penelitian ini mengikuti alur tindakan yang dikembangkan oleh Norton (2009: 69) yaitu (a) perencanaan (plan), (b) pelaksanaan (act), (c) 
pengamatan (observe), dan (d) refleksi (reflect) yang akan membentuk suatu siklus. Siklus ini dilakukan terus-menerus sampai kriteria yang ditetapkan dalam setiap tindakan tercapai.

a. Merencanakan (planning)

Kegiatan merencanakan meliputi (i) menyusun Satuan Acara Tutorial (SAT), Lembar Kerja Tutorial (LKT), lembar pengamatan, (ii) menyiapkan media yang dibutuhkan yaitu LCD, dan (iii) mengkoordinasikan program kerja pelaksanaan tindakan dengan penanggungg jawab wilayah (PW).

b. Melaksanakan (acting)

Melaksanakan tindakan disesuaikan dengan SAT yang telah disusun, yaitu tutorial dengan diskusi eksploratif yang menekankan pada pengetahuan metakognitif pada modul Pengantar Statistika.

c. Mengamati (observing)

Mengamati dilakukan selama kegiatan pelaksanaan tindakan berlangsung. Pengamatan dilakukan oleh 4 (empat) orang pengamat. Objek yang diamati meliputi aktivitas peneliti sebagai tutor dan aktivitas mahasiswa selama kegiatan tutorial berlangsung.

d. Refleksi (reflecting)

Tahap ini meliputi kegiatan memahami, menjelaskan, dan menyimpulkan data. Peneliti merenungkan hasil tindakan I sebagai bahan pertimbangan apakah siklus sudah mencapai kriteria atau tidak. Jika kriteria tindakan telah tercapai maka penelitian berhenti, jika belum tercapai, peneliti masuk ke siklus II, begitu seterusnya. Adapun kriteria keberhasilan dalam setiap siklus adalah hasil tes lebih besar atau sama dengan 70 (skor 0-100) dan semua kelompok aktif dalam diskusi yang ditunjukkan minimal satu aspek muncul 1 kali di setiap kelompok untuk semua tahapan tutorial (kegiatan awal, inti, dan penutup).

\section{HASIL DAN PEMBAHASAN}

Tindakan I dilaksanakan pada Minggu, 16 Agustus 2009, sedangkan tindakan II pada 23 Agustus 2009. Selama mengikuti kegiatan perbaikan tutorial, mahasiswa terlihat aktif berdiskusi. Terjadi pola interaksi mahasiswa-mahasiswa yang merupakan prinsip tutorial ke-8. Hal ini ditunjukkan oleh hasil observasi Siklus I dimana (a) rata-rata 3 kali anggota setiap kelompok mencari informasi dari LKT/buku, (b) 2 kali mengajukan pertanyaan atau permasalahan, (c) 4 kali mendengarkan informasi, ide, jawaban dan pertanyaan dari tutor dan teman, dan (d) 3 kali merespon informasi, ide, jawaban dan pertanyaan dari tutor dan teman. Hal yang serupa juga terjadi di Siklus II, bahkan terjadi peningkatan kuantitas yaitu (a) rata-rata 6 kali anggota setiap kelompok mencari informasi dari LKT/buku, (b) 4 kali mengajukan pertanyaan atau permasalahan, (c) 7 kali mendengarkan informasi, ide, jawaban dan pertanyaan dari tutor dan teman, dan (d) 6 kali merespon informasi, ide, jawaban dan pertanyaan dari tutor dan teman.

Hasil di atas juga menunjukkan bahwa mahasiswa secara mandiri menggali informasi/pengetahuan sendiri dari berbagai sumber belajar (prinsip tutorial ke-4). Hal ini ditunjukkan dengan 3 dan 6 kali anggota setiap kelompok mencari informasi dari LKT/Buku pada Siklus I dan II secara berurutan. Di samping juga dari 4 dan 7 kali anggota setiap kelompok mendengarkan informasi dari tutor dan teman pada Siklus I dan II secara berurutan.

Selama kegiatan perbaikan tutorial juga tampak adanya diskusi, komentar dan kritik antarmahasiswa (prinsip tutorial ke-6). Hal ini terlihat dari kegiatan diskusi kelompok di mana mahasiswa mengajukan pertanyaan rata-rata sebanyak 2 dan 4 kali dalam Siklus I dan II secara 
berurutan. Juga ditunjukkan dari kegiatan mahasiswa merespons ide, pendapat, jawaban dan pertanyaan dari tutor dan teman rata-rata sebanyak 3 dan 6 kali pada Siklus I dan II secara berurutan. Kegiatan mahasiswa pada waktu diskusi ini dapat dilihat pada Gambar 1.

Setelah melakukan diskusi kelompok, tutorial dilanjutkan dengan diskusi kelas dimana pada diskusi ini mahasiswa mempresentasikan hasil diskusi. Kelompok lain merespon/bertanya mengenai hasil presentasi, dan kelompok penyaji menyampaikan argumen jawaban. Dari hasil pengamatan tampak bahwa aktivitas-aktivitas itu muncul dalam diskusi kelas. Berdasarkan hasil diskusi ini, tutor memfasilitasi suatu kesimpulan yang menjadi pengetahuan bagi mahasiswa. Ini berarti kesimpulan/keputusan dalam tutorial diambil melalui proses dinamika kelompok di mana setiap mahasiswa dalam kelompok memberikan sumbang pikirannya (prinsip tutorial ke-7). Kegiatan diskusi kelas ini dapat dilihat pada Gambar 2.
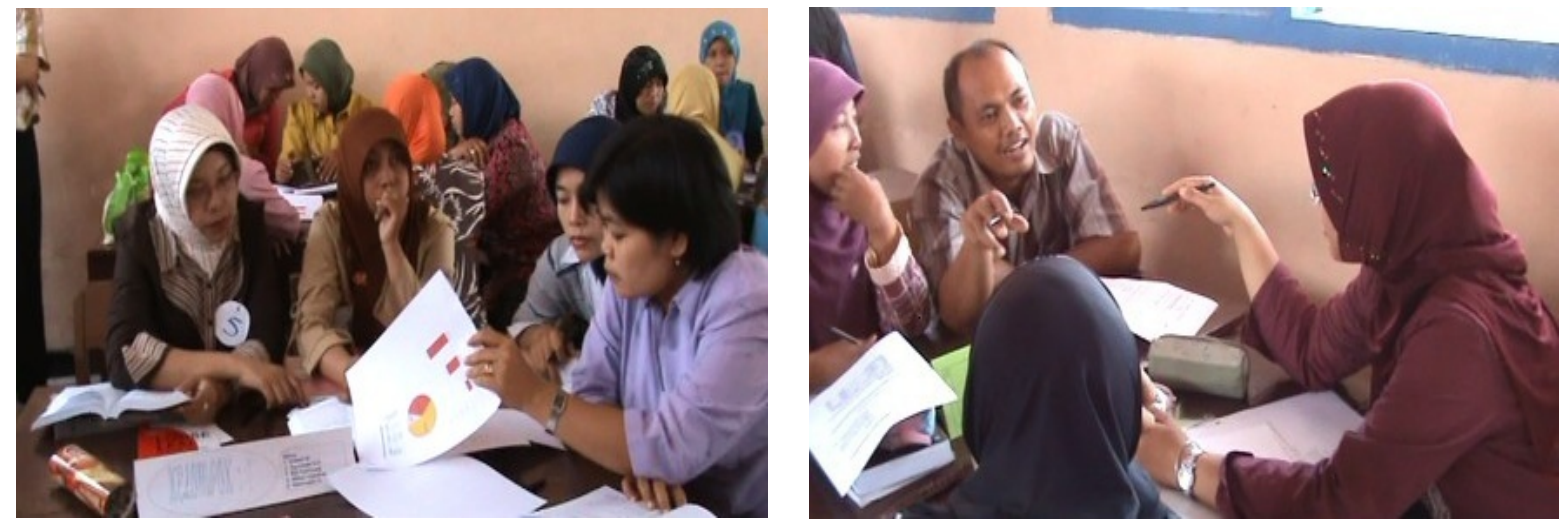

Gambar 1. Kegiatan mahasiswa pada waktu diskusi kelompok
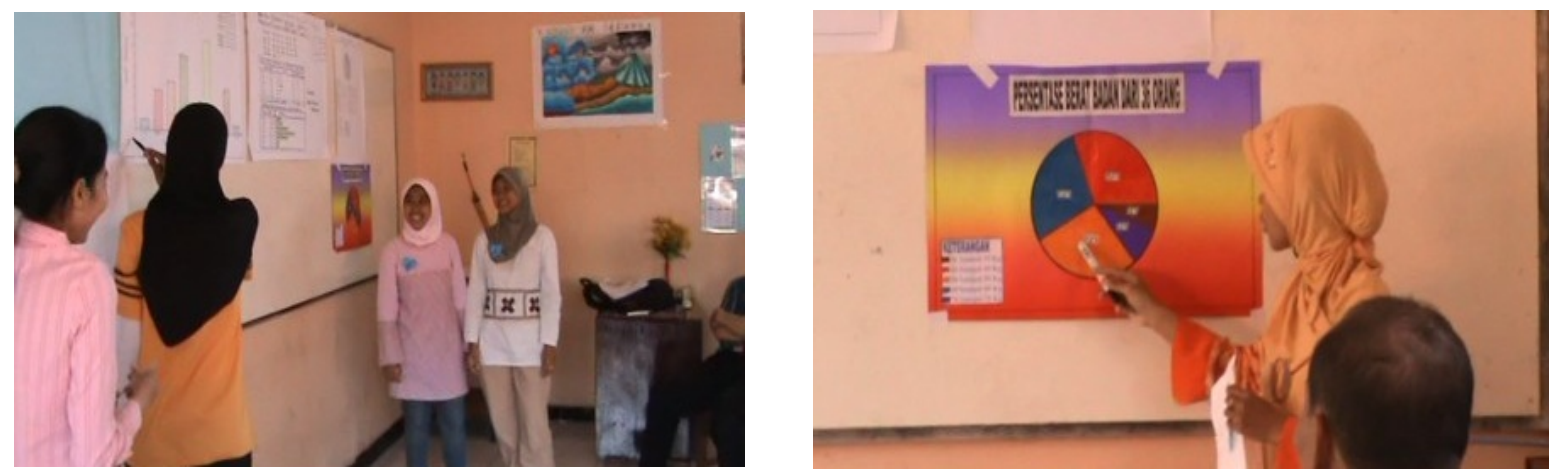

Gambar 2. Kegiatan mahasiswa pada waktu diskusi kelas

Dalam melakukan kegiatan perbaikan tutorial, tutor menggunakan media dan metode bervariasi guna merangsang mahasiswa untuk belajar. Pada Siklus I, tutor mendorong mahasiswa untuk belajar mandiri melalui pemberian proyek yaitu membuat diagram secara kelompok di luar jam tutorial, tanpa mahasiswa memberikan informasi mengenai bagaimana bentuk diagram yang dimaksud dan cara membuatnya. Selanjutnya, diagram tersebut dipresentasikan dengan media karton yang kemudian ditempel di depan kelas. Tutor menggunakan media ini untuk memungkinkan 
mahasiswa memiliki pemahaman yang mendalam (indepth understanding). Pada Siklus II, tutor menggunakan slide powerpoint yang ditampilkan melalui LCD dalam diskusi kelompok dan kelas. Tujuannya agar mahasiswa termotivasi untuk belajar ukuran pemusatan. Selain itu, tutor juga menggunakan pertanyaan-pertanyaan dalam LKT untuk mendorong siswa agar belajar secara mandiri mengenai cara mencari rata-rata, median dan modus, tanpa diberikan petunjuk oleh tutor. Kegiatan perbaikan ini telah memenuhi prinsip tutorial ke-10 yaitu tutor seyogyanya mampu membuat variasi stimulasi/rangsangan untuk belajar.

Selain itu, perbaikan tutorial yang telah disusun dan dilaksanakan peneliti juga mampu mendorong mahasiswa untuk belajar secara mandiri. Hal ini ditunjukkan oleh mahasiswa, yang mampu membuat diagram dan mencari ukuran-ukuran pemusatan. Bukan hanya mampu membuat, mahasiswa masing-masing kelompok juga mampu menjelaskan bagaimana membuat diagram tersebut dan dapat menceritakan isi dari diagram yang dibuatnya.

Selama diskusi kelompok, tutor memberikan bantuan (scaffolding) ke kelompok yang mengalami kesulitan dalam menjawab pertanyaan-pertanyaan dalam LKT. Bantuan diberikan tidak dengan memberitahukan jawaban, tetapi pada hal-hal kunci yang dapat digunakan mahasiswa untuk menjawab pertanyaan-pertanyaan tersebut. Hal-hal kunci itupun diberikan melalui tanya jawab atau diskusi tutor-mahasiswa atau dapat juga tutor meminta partisipasi setiap anggota kelompok untuk memberikan pendapatnya. Sebagai contoh, untuk memahami makna dari ukuran pemusatan, tutor bertanya pada mahasiswa dalam kelompok, "Apa maksud rata-rata tinggi badan kelas B adalah 165 $\mathrm{cm}$ ?" Dalam proses itu, tutor menghindari diri dari upaya memberikan pendapat terhadap kebenaran dan kualitas komentar mahasiswa (prinsip tutorial ke-5). Melalui proses pemberian bantuan ke kelompok-kelompok, tutor telah memberikan bimbingan kepada mahasiswa dengan teliti dalam keseluruhan langkah proses belajar yang dijalani mahasiswa (prinsip tutorial ke-2) dan bertanggungjawab atas proses belajar dalam kelompok (prinsip tutorial ke-13).

Pada waktu diskusi kelas, tutor mengeksplorasi apa yang telah diketahui dan belum diketahui oleh mahasiswa yaitu dengan bertanya dan meminta mahasiswa untuk menjelaskan hasil diskusi kelompoknya masing-masing. Salah satunya adalah meminta mahasiswa menjelaskan cara pembuatan diagram, meminta umpan balik dari mahasiswa kelompok lainnya, atau bertanya kembali untuk memperjelas jawaban mereka. Pada waktu mengeksplorasi itu, tutor menggunakan pertanyaan-pertanyaan metakognitif seperti kenapa dan mengapa. Sebagai contoh, kenapa rata-rata, median dan modus disebut ukuran pemusatan? Kalau begitu, coba kalian definisikan apa yang dimaksud dengan ukuran pemusatan. Kenapa pada histogram untuk data tinggi atau berat badan, batangnya harus berimpitan? Berdasarkan pada jawaban mahasiswa ini, tutor mendorong mereka untuk mencapai bukan hanya pada tingkat pengertian, tetapi sampai tingkat pengertian yang mendalam. Ini berarti kegiatan perbaikan tutorial sesuai dengan prinsip tutorial ke-1 (yaitu interaksi tutor-mahasiswa berlangsung pada tingkat metakognitif), ke-3 (yaitu tutor harus mampu mendorong mahasiswa sampai pada taraf pengertian), ke-9 (tutor perlu melakukan pelacakan lebih jauh), dan ke-11 (yaitu tutor selayaknya memantau kualitas kemajuan belajar mahasiswa dengan mengarahkan kajian sampai pada tingkat pengertian yang mendalam).

Dari hasil tes menunjukkan peningkatan yang signifikan dari tes awal ke tes akhir masingmasing siklus. Khusus pada Siklus II, rata-rata tes akhir mahasiswa adalah 95,8 > 70, sedangkan tes awalnya 35,3 (meningkat 170\%). Ini berarti perbaikan tutorial juga dapat meningkatkan pemahaman mahasiswa terhadap modul Pengantar Statistika yang ditunjukkan dengan peningkatan hasil tes itu. 
Berdasarkan penjelasan di atas maka perbaikan tutorial yang dilaksanakan dengan diskusi eksploratif selain dapat meningkatkan pemahaman mahasiswa terhadap modul Pengantar Statistika, juga memenuhi prinsip-prinsip tutorial yaitu prinsip 1 -11.

\section{KESIMPULAN DAN SARAN}

Berdasarkan hasil penelitian yang diperoleh dapat disimpulkan bahwa kegiatan tutotial menggunakan metode diskusi eksploratif yang menekankan pada pengetahuan metakognitif dapat meningkatkan pemahaman dan kemandirian mahasiswa S1 PGSD Pokjar Sidoarjo pada modul Pengantar Statistika. Hal ini ditunjukkan dari hasil tes dan pengamatan. Hasil tes menunjukkan peningkatan secara signifikan dari tes awal ke tes akhir masing-masing siklus. Khusus pada Siklus II, rata-rata tes akhir mahasiswa adalah 95,8 > 70, sedangkan tes awalnya 35,3 (meningkat 170\%). Hasil pengamatan menunjukkan bahwa kegiatan tutorial memenuhi prinsip tutorial 1-11, dimana prinsip-prinsip itu menuntut kemandirian mahasiswa dalam belajar.

Selain itu, penelitan ini masih mungkin diperbaiki dan dikembangkan lebih lanjut. Misalnya, penelitian ini baru dilaksanakan di dua modul yaitu Pengantar Statistika I dan II, sedangkan mata kuliah Matematika memiliki 12 modul. Ini berarti masih terbuka kemungkinan untuk menggunakan metode diskusi eksploratif yang menekankan pada pengetahuan metakognitif untuk modul-modul lainnya. Tujuannya adalah untuk memperoleh gambaran menyeluruh mengenai penggunaan metode ini pada mata kuliah Matematika.

\section{REFERENSI}

Anderson, J. \& Krathwohl, D. R. (2001). A taxonomy for learning teaching and assessing: A revision of blooms taxonomy of educatinal objectives. Addison Wesley Longman, Inc USA

CORD. (2005). The REACT Strategy. Diambil tanggal 5 April 2009 dari: http://www.cord.org/the-reactstrategy.

Flavell. (1979). Metacognition and cognitive monitoring. Boston: Allyn Bacon.

Gama, C. A. (2004). integrating metacognition instruction in interactive learning environments. Disertasi, University of Sussex.

Hudojo, H. (2005). Kapita selekta pembelajaran matematika. Malang: IMSTEP.

NCREL. (1995). Metacognition-thinking about thinking-learning to learn. Diambil tanggal 6 Mei 1995 dari: (http://members.iinet.net.au/metacognition.htm)

Norton, L. (2009). Action research in teaching and learning: A practical guide to conducting pedagogical research in university. London: Routledge. 